\title{
DO CAD AO DAD: A CONSTRUÇÃO DE UMA TERRITORIALIDADE ALICERÇADA NA PRÁTICA TEATRAL NA UNIVERSIDADE
}

\author{
Juliana Wolkmer \\ Mestranda no Programa de Pós-Graduação em Artes Cênicas \\ da Universidade Federal do Rio Grande do Sul \\ E-mail: jwolkmer@yahoo.com.br \\ Vera Lúcia Bertoni dos Santos \\ Professora Associada do Departamento de Arte Dramática \\ da Universidade Federal do Rio Grande do Sul \\ Professora do Programa de Pós-Graduação (Mestrado e Doutorado) em Artes Cênicas \\ E-mail: bertonica@gmail.com
}

\section{Resumo}

O trabalho propõe-se a refletir sobre aspectos da construção da territorialidade do Departamento de Arte Dramática (DAD) do Instituto de Artes da Universidade Federal do Rio Grande do Sul (IA/ UFRGS), enquanto espaço institucional de prática artística e formação em teatro na cidade de Porto Alegre (RS). O conceito de territorialidade é abordado a partir da perspectiva do historiador teatral Jorge Dubatti (2008), que considera o teatro uma prática sempre inserida em um contexto geográfi$\mathrm{co}$, histórico e cultural. Como a territorialidade não pode ser vista como fenômeno a priori, busca-se problematizar a construção do referido espaço, através de relatos memoriais que remontam 0 momento inicial de constituição do DAD, outrora denominado Curso de Arte Dramática (CAD). A demanda existente na cidade por um Curso de Teatro e os discursos dos sujeitos que lutaram pela consolidação de um espaço para o ensino de teatro dentro da universidade são os pontos de partida deste trabalho. A noção de "convívio teatral", definida por Dubatti como o encontro de corpos presentes que estabelecem vínculos e afeições em um dado território, permite pensar o CAD como um espaço propulsor de experiências, práticas artísticas e subjetividades que perduram até a atualidade, caracterizando o DAD de forma diferenciada dentro da universidade e para além dos seus muros.

Memória. Territorialidade. Formação Acadêmica. Teatro. UFRGS.
Abstract

The paper proposes to reflect on aspects of construction of territoriality of the Department of Dramatic Art (DAD) from the Arts Institute of the Federal University of Grande do Sul (IA/UFRGS), as an institutional space of artistic practice and training in theater in the city of Porto Alegre (RS). The concept of territoriality is approached from the perspective of the theatrica historian Jorge Dubatti (2008), which considers the theater a practice always inserted in a geographical, historical and cultural context. Since territoriality cannot be seen as a priori phenomenon, the paper proposes to analyze the construction of this space through memorials reports going back to the initial moment of creation of the DAD, formerly called Course of Dramatic Art (CAD). The existing demand in the city for a theater college and the speeches of the subjects who fought for the consolidation of a space for higher theater education are the starting points of this work. The notion of "living theater", defined by Dubatti as a reunion of present bodies that establish ties and affections in a given territory, allows us to think about the CAD as a propellant space experiences, artistic practices and subjectivities that persist to the present day, featuring the DAD differently within the university and beyond its walls. Keywords Memory. Territoriality. Higher Education. Theater. UFRGS. 


\section{Introdução}

Um espaço que se pretenda de formação e de convívio é fatalmente investido de valores materiais, educacionais, éticos, simbólicos e afetivos. $E$ as relações sociais nele travadas produzem territorialidades, que, por conseguinte, engendram novas relações sociais, num ciclo de modificações e constantes variáveis. Sendo assim, os espaços de formação acadêmica são constituídos a partir da diversidade de valores emergentes das inúmeras conexões estabelecidas entre os sujeitos, principalmente docentes e discentes, que tornam único, e repleto de especificidades, o espaço de ensino no qual convivem.

A motivação central deste trabalho é a necessidade de refletir sobre as origens do Departamento de Arte Dramática (DAD) do Instituto de Artes (IA) da Universidade Federal do Rio Grande do Sul (UFRGS), considerando a sua relevância como espaço de formação acadêmica de atores, diretores e professores de teatro e a vocação transformacional que a sua história evidencia.

Nesse sentido, o seu objetivo central é evidenciar as condições de emergência do surgimento desse espaço institucional propulsor de práticas artísticas e pedagógicas e formador de grande parte dos artistas e professores de teatro atuantes na cidade de Porto Alegre e destacados dentro e fora do estado, com vistas a refletir acerca da construção da territorialidade desse lugar, dados os aspectos físicos e geográficos e as dimensões históricas e políticas que englobam comportamentos e relações específicas que nele se constroem.

O estudo aprofundado de fenômenos relacionados ao teatro leva a considerar a territorialidade como um aspecto fundamental a ser investigado:

Entende-se por territorialidade a consideração do teatro em contextos geográfico-histórico-culturais de relação e diferença quando contrastados a outros contextos [...] A territorialidade do comparatismo vincula-se ao pensamento da "geografia humana", iniciado por Paul Vidal de La Blache. A territorialidade é construída através das práticas culturais do homem, sendo uma delas o teatro. O fato de considerar o teatro em contextos culturais não o exclui de ser parte deles: o teatro mesmo é gerador e construtor das variáveis desses contextos (Dubatti, 2008, p. 15, tradução nossa').

De acordo com o historiador teatral Jorge Dubatti, o conceito de territorialidade, não pode ser visto como um fenômeno a priori, pois "[...] não existe comparatismo quando a territorialidade se dá por sentada, como um fenômeno dado a priori, ou quando ela é ignorada sem problematização" (Dubatti, 2008, p. 16, tradução nossa²). Essas considerações de Dubatti suscitam algumas questões exploradas neste texto, tais como: a real demanda existente em Porto Alegre, no final da década de 1950, que viesse a justificar a abertura de um Curso de Teatro dentro da universidade; os perfis e as motivações dos sujeitos que lutaram pela existência do referido Curso; e o desenrolar das etapas da construção do espaço que

\footnotetext{
1 Se entiende por territorialidad a consideración del teatro en contextos geográfico-histórico-culturales de relación y diferencia cuando se los contrasta com otros contextos [...]. La territorialidad del comparatismo se vincula com el pensamiento de la "geografia humana", iniciado por Paul Vidal de La Blache. La territorialidad se construye através de las prácticas culturales del hombre, una de las cuales es el mismo teatro. El hecho de considerar al teatro en contextos culturales no lo excluye de ser parte de ellos: el teatro mismo es generador y constructor de las variables de esos contextos (Dubatti, 2008, p. 15).
}

$2[\ldots]$ no hay comparatismo cuando la territorialidad se da por sentada, como un fenómeno dado o a priori, o cuando se la ignora sin problematización (DUBATTI, 2008, p. 16). 
hoje se denomina DAD. Evidentemente não se pretende aqui fornecer respostas acabadas a esses questionamentos, mas sim partir deles como disparadores para a investigação de fatos da história do antigo CAD, atual DAD, que permitem refletir sobre a noção de territorialidade desse espaço de formação acadêmica de profissionais de teatro.

Expressos em relatos memoriais de sujeitos que participaram diretamente dessa história, ou estiveram à frente dos acontecimentos que constituem a territorialidade do CAD e do DAD, esses fatos são verificados em diversas fontes, tais como: documentos do acervo do Arquivo Histórico do Instituto de Artes da UFRGS, publicações, especialmente a Revista Cena, do Programa de Pós-Graduação em Artes Cênicas (PPGAC) e do DAD, do Sistema de Periódicos da UFRGS, e entrevista ${ }^{3}$ concedida especialmente para a elaboração deste trabalho. A análise dos dados coletados dessas fontes possibilita problematizar o DAD enquanto um espaço vivo e intenso, que transforma e é transformado por aqueles que nele inscrevem um pouco da sua própria história.

\section{A construção de} uma territorialidade

O comparatismo surge na problematização da territorialidade a partir de alguns aspectos, dentre eles o histórico, que pode ser diacrônico - quando envolve fenômenos de sucessão,

3 O entrevistado foi o professor e diretor de teatro Luiz Paulo Vasconcellos, que recebeu a pesquisadora Juliana Wolkmer na sua residência em Porto Alegre, em março de 2016. A entrevista, do tipo semi-estruturada, desenvolveu-se a partir de um roteiro com questões abertas, desencadeando uma conversa espontânea e produtiva, vindo a constituir a primeira de uma série de entrevistas em andamento na pesquisa, com o propósito de levantar dados, comparar ou complementar as informações históricas coletadas nas demais fontes mencionadas no texto. permanência ou transformação, ou sincrônico - relativo a fenômenos simultâneos (Dubatti, 2008). A pensar a partir de Dubatti, que o reconhecimento da territorialidade passa pelo exercício comparativo, e a considerar que a territorialidade do DAD é um tema quase inexplorado, entende-se que a comparação da sua territorialidade com a territorialidade de qualquer outra instituição de ensino superior dedicada ao Teatro implique, necessariamente, o desafio de colher e organizar informações que possibilitem reconstruir a história que alicerça a constituição do DAD e, assim, problematizar a sua territorialidade, tornando possível o exercício comparativo.

A consolidação do ensino de teatro na UFRGS partiu de uma necessidade da comunidade cultural de Porto Alegre, que viu crescer o movimento teatral nos anos 1940 e 1950, configurando-se um fenômeno histórico diacrônico de transformação, num momento em que artistas como Walmor Chagas, Paulo José, José Lewgoy, Antônio Abujamra, Lilian Lemmertz e Paulo César Pereio ganhavam destaque na cena gaúcha. Os jovens artistas, que então despontavam na cena local, almejavam uma maior qualidade das suas encenações e interpretações, assim como a ampla divulgação de textos teatrais consagrados.

A inspiração para a renovação do movimento teatral porto-alegrense emanava do Rio de Janeiro (com a companhia Os comediantes, por exemplo) e de São Paulo (com Teatro Brasileiro de Comédia - TBC), onde encenadores estrangeiros eram convidados a colaborar, qualificando e profissionalizando a cena teatral. O sentimento que movia os jovens artistas de teatro de Porto Alegre encontrava eco nos acontecimentos teatrais do chamado "eixo Rio - São Paulo", caracterizando um fenômeno 
histórico sincrônico (Dubatti, 2008), no qual os "teatreiros" da capital gaúcha também se engajavam na luta pela renovação e profissionalização da arte teatral.

Artistas pertencentes ao Teatro do Estudante, ao Clube do Teatro, ao Teatro Universitário, ao Teatro de Equipe, à Comédia da Província, à Sociedade Teatro do Sul, dentre outros grupos locais, que eram, em sua maioria, compostos por alunos de vários cursos da UFRGS, especialmente do curso de Filosofia, reuniam-se no bar da faculdade e no centro acadêmico ${ }^{4}$, onde, dentre outros assuntos, discutiam os rumos do teatro porto-alegrense. Esses jovens idealizavam concepções inovadoras de teatro que fugissem do teatro comercial e meramente recreativo: desejavam um espaço dentro da universidade para aprofundar a pesquisa das práticas artísticas que fervilhavam pela cidade graças a iniciativas particulares.

No dia 30 de dezembro de 1957, após reiterados esforços e pressões junto às instâncias competentes da universidade, foi fundado o Curso de Arte Dramática (CAD), que iniciaria suas atividades a partir do ano de 1958, ligado à Faculdade de Filosofia da UFRGS, com o objetivo de formar atores. Os interessados pela arte teatral, como o crítico teatral, ator, diretor e pesquisador Cláudio Heemann (1933-1999), puderam, enfim, dar vazão ao desejo de estudar teatro em âmbito acadêmico:

Nos anos 50, nós que havíamos lutado pela criação do curso ficamos surpresos e encantados com a prontidão da universidade em atender a sugestão do nosso movimento. Por uma questão de coerência fizemos todos a inscrição para o vestibular prático-

4 Situado no Campus Central da UFRGS, o centro acadêmico do curso de Filosofia era uma espécie de sede não oficial do movimento que reivindicava um Curso de Teatro dentro da universidade. teórico, entrando felizes para a universidade, como num sonho. ĺamos estudar o objeto de nossa paixão, Teatro (Heemann, 2000, p. 31).

O diretor de teatro, ator, crítico e autor teatral italiano Ruggero Jacobbi (1920-1981), que colaborava com o movimento de renovação do teatro ${ }^{5}$ em São Paulo e no Rio de Janeiro, foi convidado para assumir a direção do CAD, tendo como assessores o diretor de teatro, ator e escritor Fernando Peixoto (1937-2012) e o ator, escritor e tradutor Linneu Dias (1928-2002). Intelectual de nível extraordinário, Jacobbi dirigiu o CAD de modo humanístico e libertário durante os dois primeiros anos de existência do curso. Os trechos do seu discurso, proferido na aula inaugural do Curso de Teatro, ministrada no dia 10 de abril de 1958, revelam as nobres aspirações que moveram a criação do CAD:

Queremos ser os herdeiros e os conservadores de uma tradição, e ao mesmo tempo queremos nos libertar da obrigação de dependermos unicamente dessa tradição. Queremos ressalvar nosso direito de escolhermos livremente, sobretudo dentro das formas novas [...] A nossa época é uma época de inquietações, de provações, mas sobretudo, uma época de procura. Estamos procurando, com a mesma ansiedade, um estilo de representação que convenha ao nosso tipo de homem histórico, e uma categoria de situação, isto é, um drama, um repertório capaz de identificar-nos [...] A única atitude respeitável para o teatro de hoje consiste em pôr a prova, até o extremo limite de nossas energias, tudo o que sentimos vibrar de vida humana, de protesto, de revolta. Qualquer tentativa de acorrentar essa exigência de liberdade a teses e pro-

\footnotetext{
5 Com o término da Segunda Guerra Mundial (1939-1945), o teatro na Itália encontrava-se totalmente enfraquecido, fato que trouxe ao Brasil uma série de profissionais extremamente qualificados como Ruggero Jacobbi, Gianni Ratto, Adolfo Celi, entre outros italianos.
} 
gramas rígidos deve ser considerada uma ameaça grave. Até mesmo a ambiguidade é importante e necessária (Jacobbi, 2000, p. 6).

No discurso de Jacobbi evidencia-se o objetivo do Curso de Teatro de desenvolver a prática artística na universidade, não para limitá-la aos moldes de um curso acadêmico ou circunscrevê-la a padrões estéticos, mas para aprofundar os estudos e conhecimentos acerca do fazer teatral. O CAD nasce, portanto, como lugar de oportunidade, experimentação, descoberta, criação, questionamento e liberdade artística.

A sede provisória do recém-criado $C^{2} D^{6}$ era um casarão amarelo antigo, que abrigara um açougue, localizado no Bairro Santana, na esquina da Avenida Venâncio Aires com a Rua Santana, próximo ao Parque Farroupilha (Parque da Redenção). O espaço destinado ao funcionamento do CAD era restrito e pouco adequado ao desenvolvimento de um Curso de Teatro, mas essa adversidade não impossibilitou o afeto dos estudantes pelo espaço, fato que se constata no depoimento da atriz e professora Haydée Porto, que relembra seus tempos de estudante do CAD, vividos no final da década de 1960:

Não existe mais a casa e eu não tenho fotos (alguém tem?), mas as noites passadas lá eu lembro como um filme, desses que a gente lembra até da cor da meia do coadjuvante na cena em que ele abre a porta do carro pra mocinha (Porto, 2000, p. 36).

Observe-se que as condições materiais precárias para o desenvolvimento do Curso, que poderiam desestimular os estudantes e pro-

6 No ano de 1958 o Curso funcionou junto ao prédio da Faculdade de Filosofia, em 1959 passa a funcionar com sede própria na Avenida Venâncio Aires. fessores, serviram de inspiração para ativar a potência libertadora e transformadora da arte teatral, conforme consta no discurso de Jacobbi (1958) na aula inaugural:

Hoje, a anarquia dos valores é um fato. Como poderia nosso mundo dilacerado possuir uma estrutura cênica adequada? A indecisão, a confusão e a multiplicidade não passam de uma consequência lógica [...] Que nos importa o esquálido teatro de hoje em dia, e sua péssima arquitetura, se de qualquer maneira apagamos as luzes, antes de começarmos a representar? Não é um belo sintoma de vitalidade e da necessidade da arte teatral o fato de que ela se sirva de matérias usadas, de resíduos, de ruínas, para transformá-los em uma nova substância vitoriosa? (Jacobbi, 2000, p. 8)

O Curso de Arte Dramática, voltado à formação de atores profissionais, admitia alunos por meio de uma seleção composta por quatro etapas: exame de cultura geral; apresentação de um texto memorizado, de livre escolha do candidato; leitura de um texto sorteado pela banca examinadora; e teste de improvisação.

O Curso tinha sua duração prevista em três anos e contava com três disciplinas principais - "Interpretação", "Elementos de mímica e dança" e "Técnica de voz" - e outras disciplinas que se somavam ao currículo.

Além do Curso de Arte Dramática, a universidade oferecia o Curso de Cultura Teatral (CCT), que funcionava anexo ao Departamento de Letras e era voltado principalmente a estudantes universitários, mas com algumas vagas para intelectuais, professores e pessoas interessadas em aprender sobre teatro. O CCT tinha duração prevista em dois anos e contava com três disciplinas: "Teoria geral do teatro", "História da literatura dramática" e "História do teatro português e brasileiro". Para o CCT 
não havia processo seletivo: suas vagas eram preenchidas conforme ordem de inscrição.

Os dois cursos exigiam a frequência mínima de dois terços das aulas, sendo que, no CAD, ao final de cada ano, os estudantes realizavam provas escritas para as disciplinas de cultura teatral e provas práticas para as disciplinas de arte dramática, sendo aprovados os alunos com nota igual ou superior a cinco; e, no CCT, não havia exames finais, apenas exigência de frequência.

No seu primeiro ano de existência (1958), o CAD e o CCT contavam com os seguintes professores: Ângelo Ricci, Guilhermino César, Madeleine Ruffier, Tony Petzhold, Ruggero Jabobbi e Gerd Bornheim.

A disciplina de Interpretação do CAD realizava seus exames na forma de espetáculos teatrais abertos ao público. Os exames possibilitavam aos estudantes a participação em todas as etapas da realização de um espetáculo nas mais variadas funções: produção, assistência de direção, atuação, execução de cenários, figurinos e adereços, assim como divulgação. O grande envolvimento dos estudantes para a concretização dos espetáculos fazia do CAD um espaço de experiência cultural resultante do convívio teatral:

[...] um lugar para viver - de acordo com o conceito de convívio e cultura vivente -, a poíesis não somente se olha e observa, mas se vive. Expectação deve ser considerada como sinônimo de viver-com, perceber e deixar que se afetem todas as esferas das capacidades humanas pelo ente poético em convívio com os outros (artistas, técnicos, espectadores) (Dubatti, 2008, p. 43, tradução nossa ${ }^{7}$.

7 [...] um lugar para vivir - de acuerdo al concepto de convivio y cultura viviente -, la poíesis no solo se mira u observa sino que se vive. Expectación por lo tanto debe ser considerada como sinónimo de vivir-con, percibir y dejar se afectaren todas
Assim, o planejamento didático do primeiro ano do Curso previa a montagem de uma tragédia, de um drama e de uma comédia (do romantismo ao expressionismo); no segundo ano, envolvia o trabalho com a Commedia Dell"Arte, com a tragédia grega e com uma peça brasileira contemporânea; e no terceiro ano, previa o trabalho em torno de um drama português ou brasileiro, de autor antigo, assim como duas peças estrangeiras modernas (uma realista e outra poética ou vanguardista). De modo geral, o Curso de Arte Dramática também propunha-se a atender às necessidades culturais e artísticas da cidade, estimulando a criação de um novo público, aberto a novas experiências estéticas:

[...] o espectador se torna consciente da natureza do ente poético a partir da frequência do seu contato com o teatro. Por sua natureza dialógica e de encontro com o outro, o teatro exige companhia, simpatia, disponibilidade e, portanto, não há expectação solipsista , da mesma forma que não há teatro "cranial". Em conclusão, o teatro é um acontecimento complexo, dentro dos qual se produzem necessariamente três sub-acontecimentos relacionados: convívio, poiesis corporal in vivo , expectação (Dubatti, 2008, p. 43 , tradução nossa ${ }^{8}$ ).

Ao longo do primeiro ano de funcionamento do CAD (1958) foram realizadas três montagens teatrais: Egmont de Goethe, $O$ novo

las esferas de las capacidades humanas por el ente poético en convivio com los otros (artistas, técnicos, espectadores) (DUBATTI, 2008, p. 43).

8 [...] el espectador va tomando conciencia de la naturaleza del ente poético a partir de su frecuentación y su contacto com el teatro. Por su naturaleza dialógica y de encuentro com el otro, el teatro exige compañía, amigabilidad, disponibilidad $y$, por lo tanto, no hay expectación solipsista, de la misma manera que no hay teatro "craneal". En conclusión, el teatro es um acontecimiento complejo dentro del que se producen necesariamente tres sub-acontecimientos relacionados: convivio, poíesis corporal in vivo, expectación (Dubatti, 2008, p. 43). 
teatro de Rossodi San Secondo e As casadas solteiras de Martins Pena.

Além da preocupação didática dos espetáculos de avaliação, que deveriam contemplar uma variedade de gêneros e estilos, visando uma formação técnica completa e versátil dos atores durante os três anos de curso, destacava-se a função cultural dos espetáculos.

As matrículas de ambos os Cursos recolhiam uma pequena taxa, o que proporcionava um fundo monetário que era usado na produção das encenações dos espetáculos dos exames públicos. Os alunos do CAD só realizavam atividades teatrais (amadoras ou profissionais) fora do Departamento com autorização escrita do diretor do Curso, pois havia o desejo de dedicação exclusiva dos alunos, visando a qualidade da formação acadêmica.

Além das aulas regulares dos Cursos, várias e importantes atividades foram promovidas no primeiro ano de existência do CAD, dentre elas: uma conferência sobre interpretação teatral proferida pelo ator e diretor polonês (radicado no Brasil) Ziembinsky; um recital de poemas brasileiros e estrangeiros; a distribuição de textos mimeografados de peças a grupos amadores; a criação do acervo da biblioteca de teatro; a preparação de um programa de rádio-teatro para a rádio da universidade; e propostas de exercícios de crítica teatral de espetáculos da cidade. Todas as atividades mencionadas colaboraram para a consolidação do CAD como um território dedicado à arte teatral, pautado pelo convívio e pela prática artística:

Chamamos de convívio, o acontecimento convival, a reunião de corpo presente, sem intermediação tecnológica, de artistas, técnicos e espectadores em uma encruzilhada territorial cronotópica (unidade de tempo e espaço) cotidiana (uma sala, uma rua, um bar, uma casa, etc) no tempo presente. O convívio, manifestação da cultura vivente, diferencia o teatro do cinema, da televisão e do rádio, pois exige a presença aurática de corpos presentes (Dubatti, 2008, p. 28, tradução nossa ${ }^{9}$ ).

A experiência do convívio teatral tende a resultar novas maneiras de compreender o mundo e estar nele enquanto sujeito participante de um coletivo. Nos primórdios da sua existência, o CAD pode ser entendido como um coletivo artístico que produziu diferentes subjetividades dentro da universidade, até então pouco acostumada a comportamentos e relações dessa ordem.

A partir de 1967, dando cumprimento à Lei 4.641, de 27 de maio de 1965, decretada no Governo Castello Branco, o Curso de Arte Dramática transformou-se no Centro de Arte Dramática, espaço voltado à formação de atores (em nível médio), diretores e professores de teatro (em nível superior). A referida lei, decretada e sancionada no início da Ditadura Militar no Brasil, dispõe sobre os cursos de teatro e regulamenta as categorias profissionais e suas correspondentes atribuições: Diretor de Teatro, Cenógrafo, Professor de Arte Dramática, Ator, Contra-regra, Cenotécnico e Sonoplasta. Tal regulamentação, pretensamente assumida pelo governo como iniciativa de valorização profissional, escondia o desejo latente de controlar o trabalho e coibir ações políticas subversivas dos artistas de teatro, condicionando

\footnotetext{
9 Llamamos convivio o acontecimiento convivial a la reunión, de cuerpo presente, sin intermediación tecnológica, de artistas, técnicos y espectadores en una encrucijada territorial cronotópica (unidad de tiempo y espacio) cotidiana (una sala, la calle, un bar, uma casa, etc) en el tiempo presente. El convivio, manifestación de la cultura viviente, diferencia al teatro del cine, la televisión y la radio en tanto exige la presencia aurática, de cuerpo presentes (Dubatti, 2008, p. 28).
} 
o exercício das suas atividades a limites e entraves burocráticos ${ }^{10}$.

Em 1969, o CAD teve a sede transferida para um casarão antigo, de dois andares, localizado na Avenida Salgado Filho, número 340, no centro de Porto Alegre, passando a contar com um teatro próprio com capacidade para 82 lugares.

$\mathrm{Na}$ época, o diretor do CAD era o professor, filósofo e crítico teatral Gerd Bornheim (1929 2002), que, amplamente apoiado por colegas professores e alunos, idealizou a realização de espetáculos de qualidade para o público, visando integrar universidade e comunidade e mostrar a relevância da formação desenvolvida no Curso de Teatro à cidade de Porto Alegre. Esse processo de qualificação dos espetáculos concebidos no Curso de Teatro contou também como ingresso de outros profissionais da área, que passaram a fazer parte do corpo docente do Curso.

Uma dessas aquisições foi a produtora de teatro gaúcha Lygia Vianna Barbosa, figura que então se destacava pelo alto nível do seu trabalho e projetava-se profissionalmente no estado do Rio Grande do Sul, que foi convidada por Bornheim para assumir a produção dos espetáculos da escola. $\mathrm{O}$ ator, diretor teatral e escritor carioca Luiz Paulo Vasconcellos também foi convidado para trabalhar no CAD: indicado pelo Conservatório de Teatro do Rio de Janeiro, veio a Porto Alegre para dirigir os estudantes do Curso de Teatro na Ópera dos Três Vinténs (1928), do dramaturgo alemão Bertold

10 No seu Artigo 11, a lei considerava legais apenas os diplomas de cursos com duração mínima de três anos e devidamente registrados no órgão competente do Ministério da Educação e Cultura. E o Artigo 14 mencionava que o requerimento para registro profissional deveria ser feito no prazo de um ano. Ou seja, a partir da publicação da lei, os atores, diretores, cenógrafos, contra-regras, cenotécnicos e sonoplastas que exerciam suas profissões há mais de dois anos sem registro foram impedidos de exercê-las.
Brecht (1898-1956), e acabou se radicando na capital gaúcha.

O espetáculo Ópera dos Três Vinténs reuniu 28 estudantes dos Cursos de Interpretação e Direção do CAD e foi apresentado numa temporada de três meses de duração, de sextas-feiras a domingos, com sessões lotadas, tornando-se o maior sucesso de público da história do CAD até então, e configurando-se como marco importante para a profissionalização do teatro gaúcho, que não estava acostumado a longas temporadas. $\mathrm{Na}$ avaliação de Vasconcellos:

\begin{abstract}
A Ópera dos Três Vinténs foi o primeiro espetáculo produzido no RS que fez uma temporada, porque antes se ensaiava quatro, cinco meses para três apresentações. E esse espetáculo ficou em cartaz, rompeu o amadorismo que caracterizava o teatro daqui [...] A temporada da Ópera dos Três Vinténs foi de junho a agosto e saiu de cartaz por causa da cassação do diretor [Gerd Bornheim]. Ela ia continuar em cartaz (Vaconcellos, 2016, p. 3).
\end{abstract}

Mas o ano de 1969 não ficaria na lembrança da comunidade do CAD somente por suas conquistas e feitos artísticos, pois foi marcado por perseguições políticas e cassações de professores da casa, como o próprio Bornheim, que foi expurgado pela ditadura militar ${ }^{11}$, como relata Vasconcellos:

Em função da cassação [de Gerd Bornheim], que na época eles chamavam de "aposentadoria compulsória", os professores do Departamento fizeram um abaixo-assinado contra o reitor e

\footnotetext{
11 O decreto-lei $\mathrm{n}^{\circ} 477$, de 26 de fevereiro de 1969, também chamado de "Al-5 das universidades", foi assinado pelo então presidente Artur da Costa e Silva, com o intuito de punir com expulsão professores, alunos e funcionários de universidades acusados de subversão ao regime militar. Os professores cassados eram impedidos de trabalhar em instituições de ensino pelo período de cinco anos; e os estudantes ficavam proibidos de cursar qualquer universidade pelo período de três anos.
} 
foram todos despedidos em função disso, então o Departamento ficou sem professor. Um dos meus primeiros desafios em 1970 foi começar a trazer os alunos do ano anterior e que estavam se formando: o Luiz Arthur [Nunes], a Irene [Brietzke]... (Vaconcellos, 2016, p. 5).

O relato do então aluno Luiz Arthur Nunes (1946), hoje diretor e dramaturgo, complementa o depoimento de Vasconcellos; e mostra como a difícil situação política vivenciada no país serviu para consolidar o CAD como um território de resistência artística:

A catástrofe nos atingiu no final do ano. Vários de nossos maiores mestres tiveram seus direitos políticos e carreira universitária roubados pelo regime militar. Professor Gerd, Professor Dionisio, Professor Ricci e sua esposa, a Professora Rina, a as duas novas Professoras recém contratadas, Maria da Glória Bordini e Reassylvia Kroeff de Souza [...] Sobraram muito poucos, entre os quais, a última aquisição de Gerd: Olga Reverbel. Nossa revolta, nosso desespero somaram-se ao medo de que aquele esvaziamento servisse de pretexto para os agentes da repressão, exigirem o fechamento da escola. Consideramos duas opções: abandonar tudo em protesto e solidariedade com os vitimados, ou ao contrário, deslanchar uma intensa atividade para provar que não fomos aniquilados, que resistíamos. Quase sem professores, os próprios estudantes tomaram a si a tarefa de propor e realizar sozinhos o trabalho teatral. Os meses seguintes viram uma febril atividade de ensaios e apresentações em que nós, os alunos, éramos os diretores, os atores, os técnicos. Resistimos. O CAD sobreviveu (Nunes, 2000, p. 47).

Os atos de resistência dos estudantes durante o período da ditadura militar, detalhados por Nunes, levam a pensar o teatro como um acontecimento ontológico (Dubatti, 2008), re- lacionado à problemática do ser, que deseja transcender através da produção dos acontecimentos poéticos, que constituem a sua existência artística no mundo. A metáfora poética faz-se necessária para o artista contrastar e pensar a realidade: "vamos ao teatro, em suma, para entrar em contato com o acontecimento do ser" (Dubatti, 2008, p. 46, tradução nossa $\left.{ }^{12}\right)$.

Até 1969, o CAD ainda era um curso pequeno, mas na década de 1970 o número de estudantes cresceu e a escola, que contava com poucos professores, foi ampliando pouco a pouco o seu corpo docente, passando a contar com os já citados, Luiz Arthur Nunes e Irene Brietzke, dentre outros, como Maria Helena Lopes, Suzana Saldanha, Graça Nunes, Sandra Dani, Ida Celina, Sérgio Silva, Ivo Bender, Alziro Azevedo, Irion Nolasco e Maria Lúcia Raymundo.

Como decorrência da Reforma Universitária de $1968^{13}$, o Centro de Arte Dramática desligase da Faculdade de Filosofia no ano de 1970, passando a denominar-se Departamento de Arte Dramática (DAD), integrado ao Instituto de Artes e ofertando os Cursos de Bacharelado em Direção Teatral e Interpretação Teatral

12 [...] vamos al teatro, en suma, para tomar contacto com el acontecimiento del ser (Dubatti, 2008, p. 46).

13 Em 1968, em plena ditadura militar, o ensino superior sofre uma reforma radical, cuja implementação foi precedida pelos acordos MEC - Usaid (Ministério da Educação e Cultura e United States Agency for International Development), que garantiram apoio técnico e financeiro para a adequação do sistema educacional brasileiro como um todo ao modelo econômico dependente de interesse norte-americano, exigindo mudanças na LDB. A Lei $n^{\circ}$. 5.540/68, "Lei da Reforma Universitária", foi baseada nos estudos do Relatório Atcon (Rudolph Atcon, teórico norte-americano) e no Relatório Meira Matos (Coronel da Escola Superior de Guerra) e teve a sua aprovação "de cima para baixo". Dentre várias outras medidas, a reforma fragmenta as Faculdades de Filosofia, Ciências e Letras, resultando na criação das Faculdades ou Centros de Educação, cujos departamentos passam a ter ligação direta à administração superior, sem instâncias intermediárias. 
e de Licenciatura em Educação Artística com Habilitação em Artes Cênicas, que a partir do segundo semestre de 2005, em função de mudanças na legislação que rege os cursos superiores, passa a chamar-se Curso de Licenciatura em Teatro.

Artisticamente, o ano de 1971 foi marcado pela primeira montagem que subverteu o uso do espaço teatral de modo convencional no Rio Grande do Sul: o espetáculo Agamenon, um trabalho do DAD, dirigido por Vasconcellos, que relembra o seu feito:

Quando eu fiz Agamenon, que foi em 1971 , foi o primeiro espetáculo montado fora de um palco convencional. Eu montei no Auditório Tasso Correa. Tiramos todas as cadeiras do auditório e foram construídos uns praticáveis nas laterais. Logo na entrada tinha um praticável baixo, depois nas laterais tinha praticáveis de dois andares e ainda tinha no palco. O espetáculo acontecia nessas várias localizações e o público no meio caminhava (Vaconcellos, 2016, p. 4).

Seria o espetáculo Agamenon, criado para desestabilizar espectadores até então acostumados a observar os acontecimentos do palco sentados confortavelmente em seus lugares na plateia, uma espécie de provocação à postura assumida por muitos, na vida real, que pareciam assistir "sentados", "calados", "conformados" ao horrendo "espetáculo" protagonizado pelos governos militares? O envolvimento político dos seus idealizadores e os ecos da encenação levam a acreditar que sim.

$\mathrm{Na}$ década de 1980, os docentes do DAD passaram a pressionar a reitoria da universidade para que destinasse um espaço que permitisse a expandir suas atividades. O espaço em questão era um então prédio abandonado, que dava fundos ao casarão da Rua Salgado Filho, onde o Curso funcionava, e cuja entrada ficava na Rua General Vitorino, número 255. Segundo o relato do então professor do Curso, Ivo Bender (1936 -), assim que a universidade sinalizou a possibilidade de anexação do prédio, a comunidade do DAD, movida pelo receio de que a reitoria voltasse atrás tratou de invadir e ocupar o espaço com suas atividades em fins da década de 1980:

E como gesto emblemático, derrubamos uma porta secreta que ligava os dois prédios. Construção de quatro pisos, gélida e ressoadora, o edifício já abrigara, em outros tempos, diferentes cursos. Desde há muito fechado, era agora refúgio de pombas e aranhas (Bender, 2000, p. 40).

Segundo Bender (2000), os professores do Curso de Teatro eram vistos por Brasília como outsiders acadêmicos, ou seja, considerados intrusos no sistema universitário, em meio a docentes de cursos tradicionalmente reconhecidos e formadores de profissionais com mercado de trabalho consolidado. Transcorridas quase três décadas da ocupação do prédio da Rua General Vitorino, ainda se questiona a posição da universidade no que diz respeito ao entendimento das especificidades dos "fazeres acadêmicos" do DAD, bem como à destinação de recursos materiais e à ampliação de vagas docentes de técnicos que venham a suprir as necessidades dos cursos de Teatro que ali se desenvolvem. Até quando os professores de Artes serão vistos como outsiders acadêmicos?

Considerações

finais

Fazer teatro é uma forma de estar vivo e o fazer teatral está ligado por natureza a uma 
prática coletiva de grupos que buscam pulsar junto, emanando saberes diversos, trocas e experimentações que se dão em tempos, espaços e circunstâncias diversas. Refletir sobre o teatro e sua territorialidade é compreender configurações e complexidades de um todo e suas partes, de forma interligada e contextualizada, com o objetivo de realizar uma leitura mais clara do passado para conectá-lo ao presente de forma mais consciente.

O CAD, atual DAD, nasceu do inconformismo e do idealismo de jovens artistas que sonhavam estudar e praticar a própria arte dentro da universidade, e trataram de inserir a prática artística na academia, conferindo a ela status de conhecimento. Esses jovens buscavam a qualificação da sua profissão aliada ao compromisso social e à difusão da cultura teatral na capital gaúcha. Apesar da pouca consciência de como o Curso de Teatro se daria de fato dentro da universidade, e considerando que seria uma experiência inédita para todos os envolvidos, Jacobbi, na sua aula inaugural, refere-se à criação do Curso num tom (dir-se-ia) profético. Jacobbi vislumbra um futuro no qual a vocação do CAD se realiza e se renova, no atual DAD, nos propósitos e ações daqueles que levam à frente o projeto de uma escola de teatro de ponta, comprometida com ideais de liberdade e inovação e voltada à comunidade da cidade que a acolhe:

Sentimos que existe uma força nesta ausência de limites; que há nisso uma liberdade nova, a qual nos abre o caminho para experiências que ainda não foram formuladas conscientemente, mas que estão dirigidas ao futuro e preservam a nossa juventude espiritual (Jacobbi, 2000, p. 7).

Daquele CAD, ao atual DAD, o Curso de Teatro da UFRGS parece ter operado apenas uma mudança de nomenclatura, pois, se por um lado é possível aos estudantes, professores, funcionários e visitantes que desfrutam do seu espaço, identificar nas memórias dos seus idealizadores muitos problemas que ainda persistem - como é o caso da carência de salas, de infra-estrutura e de pessoal ${ }^{14}$; por outro, não há como ignorar as qualidades que fazem do DAD um lugar de Teatro por excelência: um território mítico, onde o profano e o sagrado convivem, compartilham a cena sem cerimônia:

\begin{abstract}
Ali [no DAD], a qualquer hora do dia, pode-se observar a revoada dos pombos na face fronteira do edifício. São as aves de Afrodite a demarcar um território há muito pertencente à deusa. Mas se os pássaros não são evidência bastante, resta entrar na casa. O visitante notará, aqui e ali, umas nódoas escarlates entranhadas no chão. "Alguém, numa festa antiga, derramou vinho por aqui", dirá sem disfarçar a malícia no sorriso. E seguirá adiante, pisando nos rastros deixados por um bêbado Dionisos (Bender, 2000, p. 41).
\end{abstract}

Num momento emblemático em que o Curso de Teatro do Departamento de Arte Dramática da UFRGS recebe destaque em nível internacional, tendo sido classificado entre os cem melhores cursos do mundo ${ }^{15}$, esse reconhecimento territorial se faz mais do que oportuno. Torna-se mesmo imperativo!

14 Problemas que se agravam ainda mais a partir de 2007, desde a criação do almejado Programa de Pós-Graduação em Artes Cênicas (PPGAC) que também ocupa as dependências do DAD.

15 De acordo com o ranqueamento feito pela publicação britânica Quacquarelli Symonds - QS Ranking. Vide site: QS World University Rankings by Subject. 
Referências

BENDER, Ivo. De mistérios, pombos e vinho. Cena, Porto Alegre, v.1, p. 40-41, Abril, 2000.

CUNHA, Luiz Antônio. Ensino Superior e Universidade no Brasil. In: Lopes, E.M.T. et al. 500 anos de educação no Brasil. Belo Horizonte: Autêntica, 2000.

DUBATTI, Jorge. Cartografía Teatral: Introducción al Teatro Comparado. $1^{\text {a }}$ ed. Buenos Aires: Atuel, 2008.

HEEMANN, Cláudio. Quem éramos nós. Cena, Porto Alegre, v.1, p. 28-31, Abril, 2000.

JACOBBI, Ruggero. Aula Inaugural: Introdução à poética do espetáculo. Cena, Porto Alegre, v.1, p. 6-9, Abril, 2000.

NUNES, Luiz Arthur. Alma Mater. Cena, Porto Alegre, v.1, p. 45-47, Abril, 2000.

PORTO, Haydée. Tempo quente. Cena, Porto Alegre, v.1, p. 36-37, Abril, 2000.

Programa do Curso de Estudos Teatrais - Exames Públicos do Curso de Arte Dramática. Documento do Arquivo Histórico do Instituto de Artes da Universidade Federal do Rio Grande do Sul, Porto Alegre, 1958.

VASCONCELLOS, Luiz Paulo. Entrevista concedida à pesquisadora Juliana Wolkmer (Arquivo da pesquisa). Porto Alegre, março de 2016.

http://www.planalto.gov.br/ccivil_03/ leis/1950-1969/L4641.htm http://www.planalto.gov.br/ccivil_03/decreto-lei/1965-1988/Del0477.htm

Recebido em: 01/04/2016 Aprovado em: 28/09/2016 